$\varangle$ and the occasional TV project on materials and making.

The session followed with the PechaKucha, and then a lecture from Dr Fiona MacKillop, showing how the periodontal staging and grading system can be implemented effectively into your daily practice, giving examples of how we can make a diagnosis using the new system.
The closing lecture of the day was given by Dr Shanon Patel, consultant endodontist; the aim of this presentation was to give delegates an overview on how to improve the success of treatment by considering planning for success by systemically assessing the patient and the dentition, not just the tooth in question.

Many of the delegates were enthused, and said it was one of the best dental conferences they had attended, gaining new tips and ideas to reflect on, with the added bonus of CPD hours.

All in all, it was a thoroughly informative day with plenty of sound advice and specialist knowledge from the speakers.

The next Dawood and Tanner Study day will be held on 5 February 2021.

\title{
SDCEP COVID-19 guidance update
}

\author{
The Scottish Dental Clinical Effectiveness \\ Programme (SDCEP) has now modified \\ its guidance on management of \\ commonly presenting oral conditions \\ for use during the COVID-19 pandemic. \\ The new 'Management of Acute Dental \\ Problems during COVID-19 Pandemic' \\ guide is available now on the SDCEP \\ website.
}

This guide is for use by dental teams involved in triaging and managing patients during the current situation. It can be used in conjunction with health board or other local procedures that have been established for managing patients based on their COVID-19 status. Note that this guide is subject to change as new information becomes available. Therefore, please ensure

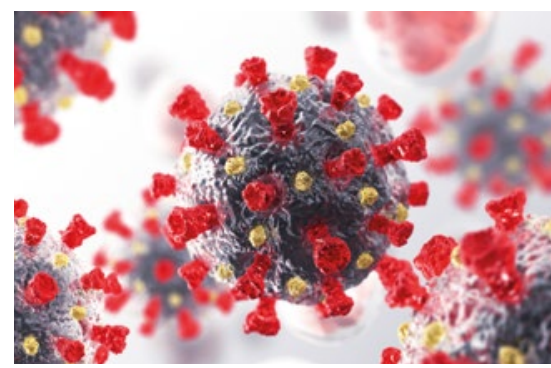

that you are viewing the most recent version by referring to www.sdcep.org.uk.

CONFERENCE REPORT

\section{'So you want to be an orthodontist'}

\section{By Prashanth Narayanan, Trust grade DCT, Level 7 Maxillofacial Department, Derriford Hospital, Plymouth}

The annual 'So you want to an orthodontist' meeting was held at the British Orthodontic Society's (BOS') headquarters in Central London on 31 October 2019.

The meeting was organised by BOS training grades group (TGG) committee representatives Miss Rupal Shah and Mr Nikhil Gogna. There were about 35 delegates attending the meeting all sharing a common passion and showing their keen interest in pursuing a career in orthodontics. It was a busy programme with talks from eminent speakers from varied backgrounds and experiences.

The programme started off with a talk from Ms Helen Tippett, orthodontic consultant, providing a detailed insight of the national recruitment process from a consultant's perspective. This was followed by a candidate's perspective of the national recruitment process - StR2 Ms Libby Richardson having successfully gone through the national recruitment process. These sessions were very informative as delegates could get an idea of what the national recruitment process entails from both perspectives. ${ }^{1}$

Given the cutthroat competition in the field of specialist training, the next session gave brilliant insight into building a robust $\mathrm{CV}$ to help maximise the chances of getting through the national recruitment process. The advice given by Mr Matt Chia, consultant orthodontist, was excellent and he gave delegates wonderful practical tips to help prepare with their application.

This was followed by a talk given by $\mathrm{Mr}$ Owaise Sharif, consultant orthodontist, who gave a summary of the various training programmes in addition to highlighting the importance of a research component as a part of orthodontic registrar training. This was soon followed by talks from current StR3 - Miss Nima Amin and Mr Othan Hameed about what specialty training entails.

The different career prospects in orthodontics after completion of specialist training was summarised by orthodontic specialist Mr John Costello and post CCST (StR5) Miss Rupal Shah. This overview of career prospects in both specialist practice and hospital provided delegates useful information regarding career options and also possibilities for future training as a consultant.

The best part of the day was the informal roundtable discussions held in the afternoon with speakers and candidates who have successfully gone through the recruitment process. This was an informal meeting where different candidates' perspectives were brought to the table and it gave an excellent opportunity for delegates to ask questions and clarify doubts, if any.

To conclude, the day provided the delegates an excellent overview of what a career in orthodontics would involve and I would definitely recommend this for anyone who is interested in specialist orthodontic training now or in the years to come.

Finally, I wish to thank the TGG committee representatives Miss Rupal Shah and Mr Nikhil Gogna for organising this wonderful meeting.

\section{Reference}

1. Richardson L. Conference report: 'So you want to be an orthodontist'. Br Dent J 2018; 224: 125. 